\title{
Radioiodine Thyroid Uptake and Scintigraphy in the Evaluation of Hyperthyroidism with Multinodular Goiter
}

\author{
M. R. Islam ${ }^{1}$, F. N. Islam ${ }^{1}$, M. H. Haque ${ }^{1}$, M. S. Hossain ${ }^{2}$, M. S. Reza ${ }^{2}$, R. Begum ${ }^{2}$ \\ ${ }^{1}$ Department of Physics, Rajshahi University, Rajshahi-6205, Bangladesh \\ ${ }^{2}$ Institute of Nuclear Medicine and Allied Sciences (INMAS), Bangladesh Atomic Energy \\ Commission, Dhaka
}

Received 15 July 2017, accepted in final revised form 31 January 2018

\begin{abstract}
The role of radioactive iodine uptake and scintigraphy were studied over 111 subjects with a mean age of $42 \pm 13$ years, $65 \%$ females and $35 \%$ males, in the evaluation of hyperthyroidism with multinodular goiter. The uptake study was performed by oral administration of $4.5-10.0 \mu \mathrm{Ci}$ of ${ }^{131} \mathrm{I}$ as sodium-iodide thyroid scintigraphy was performed 20 minutes after an intravenous injection of $2.0-4.0 \mathrm{mCi}$ of ${ }^{99 \mathrm{~m}} \mathrm{Tc}$ as pertechnetate. The Mean \pm SD uptake values for the study subjects were found to be $36.1 \pm 15.4 \%$ ranging from $14 \%$ to $75 \%$ at $2 \mathrm{~h}$ and $59.9 \pm 15.9 \%$ ranging from $32 \%$ to $90 \%$ at $24 \mathrm{~h}$ measurements. The present results of uptake values clearly exceed the normal range ( $3 \%-12 \%$ for $2 \mathrm{~h} ; 8 \%-25 \%$ for $24 \mathrm{~h}$ ), which indicate the hyper-functioning of thyroid, and therefore, demonstrated successfully the efficient role of radioactive iodine uptake and scintigraphy to diagnose the hyperthyroidism.
\end{abstract}

Keywords: Thyroid uptake; Scintigraphy; Multinodular goiter; Radioactive iodine; ${ }^{99 \mathrm{~m}} \mathrm{Tc}-$ pertechnetate.

(C) 2018 JSR Publications. ISSN: 2070-0237 (Print); 2070-0245 (Online). All rights reserved. doi: http://dx.doi.org/10.3329/jsr.v10i3.33225

J. Sci. Res. 10 (3), 223-229 (2018)

\section{Introduction}

Thyroid, the largest endocrine gland of vertebral anatomy [1,2] makes and stores hormones that helps to regulate the body metabolism, growth, development and maintenance of the internal environment $[3,4]$. Biologically active two principal thyroid hormones are thyroxine (T4) and triiodothyronine (T3), representing $99.9 \%$ and $0.1 \%$ of total secretion. These hormones increase the basal metabolic rate (BMR) and body heat production. Extreme excess of thyroid secretion cause the BMR to raise $60 \%-100 \%$ above the normal and complete lack of thyroid secretion can cause BMR to fall $40 \%-50 \%$ below

\footnotetext{
Corresponding author: mhpdru@gmail.com
} 
the normal. Thyroid hormones have a great role on physical or mental retardation of a child [5-9] and also may cause fully or partially damage of a specific organ. Especially, these hormones play a critical role during mammalian brain development [10-13].

Thyroid diseases manifest mainly by qualitative or quantitative alteration in hormone secretion. Clinical hyperthyroidism is caused by the effects of excess thyroid hormone and can be triggered by different disorders. The most common cause of hyperthyroidism [14,15] is Graves' disease (GD) followed by multinodular goiter (MNG), solitary toxic adenoma (TA) and thyroiditis (TD). Toxic MNG causes 5\% of the cases of hyperthyroidism in the United States and can be 10 times more common in iodinedeficient areas. The range of thyroid disorders other than iodine deficiencies is considered same in Bangladesh as in other countries of Asia [16]. At the beginning of the twenty first century, hypothyroidism, Graves' disease, postpartum thyroiditis and thyroid malignancies are common thyroid disorders in Bangladesh while iodine deficiency disorders are still persisting in low prevalence.

The correct management of thyroid diseases depends on accurate diagnosis, appropriate treatment and careful monitoring [17]. Clinical experience and few laboratory tests were the only means for evaluating thyroid disorders in Bangladesh even in the early eighties of the last century [18]. Based on clinical experience and guideline recommendations, radioactive iodine uptake (RAIU) measurement and scintigraphy are often requested as the first-line investigation in thyrotoxic patients [19]. The aim of the present study was to demonstrate the role of RAIU and scintigraphy in the evaluation of hyperthyroidism with multinodular goiter. The laboratory assessments of thyroid function were performed via serum measurements of ultra-sensitive thyrotropin (TSH) and free thyroxine (FT4) at the Institute of Nuclear Medicine and Allied Sciences (INMAS), Bangladesh Atomic Energy Commission (BAEC), Dhaka.

\section{Materials and Methods}

\subsection{Physical and chemical properties of iodine-131}

Iodine-131 $\left({ }^{131} \mathrm{I}\right)$ is produced commercially for medical and industrial uses through nuclear fission. It is also a byproduct of nuclear fission processes in nuclear reactors and weapons testing. The physical half-life of ${ }^{131} \mathrm{I}$ is 8.04 days after which it disintegrates into ${ }^{131} \mathrm{Xe}$ through beta and gamma emissions. The average energy of a beta particle is 0.192 $\mathrm{MeV}(89 \%)$, whereas the energy of the emitted gamma ray is $0.364 \mathrm{MeV}(81 \%)$ [20]. As a product of nuclear fission, it is a dark purple gas that can be inhaled, or absorbed through the skin. The radioactive iodine model of ICRP assumes that about $70 \%$ of ${ }^{131}$ I entered into the human body is excreted through urine and the remaining $30 \%$ settles in the thyroid gland. Furthermore, the biological half-life of radioactive iodine deposited in the thyroid gland varies, depending on the age group. ICRP assumes that it is 80 days for adults, 67 days for 15 years old, 58 days for 10 years old, 23 days for 5 years old, and 15 days for one year old [21]. 


\subsection{Physical and chemical properties of Technetium-99m}

Technetium- $99 \mathrm{~m}$ is a metastable nuclear isomer of technetium- 99 , symbolized as ${ }^{99 \mathrm{~m}} \mathrm{Tc}$. The " $\mathrm{m}$ " after its mass number 99 indicates that it is a decay product whose nucleus remains in an excited state that lasts much longer than it is typical. ${ }^{99 \mathrm{~m}} \mathrm{Tc}$ was discovered as a product of cyclotron bombardment of molybdenum. This procedure produced molybdenum-99, a radionuclide with a longer half-life (2.75 days), which decays to ${ }^{99 \mathrm{~m}} \mathrm{Tc}$. It then decays mainly by gamma emission with physical half-life of $6.0058 \mathrm{~h}$. About $98.6 \%$ of these gamma decays result in $140.5 \mathrm{keV}$ gamma rays and the remaining $1.4 \%$ are to gammas of a slightly higher energy at $142.6 \mathrm{keV}$. The relatively "short" physical half-life of the ${ }^{99 \mathrm{~m}} \mathrm{Tc}$ and its biological half-life of 1 day allows for scanning procedures. It is now used in tens of millions of medical diagnostic procedures annually due to its excellent physical properties.

\subsection{Study subjects}

A total 111 thyroid patients with a mean age of $42 \pm 13$ years, referred to the Institute of Nuclear Medicine \& Allied Sciences (INMAS), Dhaka affiliated with Bangladesh Atomic Energy Commission (BAEC) were evaluated to the functional status of their thyroid glands. The patients were from different districts of the country that include $65 \%$ females and $35 \%$ males, with ages ranging from 14 to 75 years. The thyroids of all the individuals were in clinically hyper-functioning with multinodular goiter.

\subsection{Measurement of radioactive iodine uptake}

The thyroid uptake is a measure of the rate of accumulation of certain radiopharmaceutical by the thyroid gland. The procedure of uptake measurement is relatively simple. The amount of gamma radiation given off by the radio-tracer which has been accumulated by the thyroid is compared with the amount of gamma-radiation emitted by the total dose administered to the patient. In the ideal case, both measurements should be done under identical conditions. In the present study the radioactivity counts were taken at $6 \mathrm{~cm}$, using a gamma probe. The uptake was calculated by using the wellknown equation

$$
\operatorname{RAIU}(\%)=\frac{\text { neck counts }(\mathrm{cpm})-\text { thigh counts }(\mathrm{cpm})}{\text { admin counts }(\mathrm{cpm})-\text { background }(\mathrm{cpm})} \times 100 \%
$$

Neck counts, lower thigh counts (body background), counts of the administered dose and room background counts were obtained at each counting session. A spacer was used so that the same distance was always maintained whenever counting was taken place. 


\subsection{The thyroid scintigraphy}

Scintigraphy is the use of gamma cameras to capture emitted radiation from internal radioisotopes to create two-dimensional images. At first the patients were given a $2.0-$ $4.0 \mathrm{mCi}$ intravenous dose of ${ }^{99 \mathrm{~m}} \mathrm{Tc}$-pertechnetate. Drinking water was then given immediately before performing imaging to flux away any secreted radionuclide in saliva. The patient was placed supine, and the gamma camera was placed over the neck for gamma counting. In the present study, the radioactivity in the neck of each patient was continuously recorded for $2 \mathrm{~min}$ at $30 \mathrm{~cm}$, using a gamma probe consisting of a collimated sodium-iodide crystal with a cylindrical straight-bore collimator connected to a pulse height analyzer (PHA) and scalar.

\section{Results and Discussion}

The present results of RAIU measured at $2 \mathrm{~h}$ as well as $24 \mathrm{~h}$ for all the studied patients ( $\mathrm{n}$ $=111$ ) are summarized in Table 1 . The Mean \pm SD of RAIU values separately for male and female, and their combined were found to be $37.3 \pm 16.5 \%$ at $2 \mathrm{~h}$ and $58.2 \pm 14.6 \%$ at $24 \mathrm{~h}, 34.3 \pm 14.1 \%$ at $2 \mathrm{~h}$ and $60.3 \pm 16.6 \%$ at $24 \mathrm{~h}, 36.1 \pm 15.4 \%$ at $2 \mathrm{~h}$ and $59.9 \pm 15.9 \%$ at $24 \mathrm{~h}$, respectively. All of these values are higher than the normal range [22-24] 3\% $12 \%$ for $2 \mathrm{~h}$ and $8 \%-25 \%$ for $24 \mathrm{~h}$. The present study, therefore, gives a good separation of hyperthyroid patients and none of them had uptake value within or below the normal range at both 2 and $24 \mathrm{~h}$ measurements.

Table 1. Sex wise thyroid profile of the sample population $(n=111)$.

\begin{tabular}{l|c|c|c|c|c}
\hline \multirow{2}{*}{ Sex } & \multirow{2}{*}{$n$} & \multicolumn{2}{|c|}{ RAIU range $(\%)$ at } & \multicolumn{2}{c}{ Mean \pm SD } \\
\cline { 3 - 6 } & & $2 \mathrm{~h}$ & $24 \mathrm{~h}$ & $2 \mathrm{~h}$ & $24 \mathrm{~h}$ \\
\hline Male & 39 & $13-81$ & $27-86$ & $37.3 \pm 16.5$ & $58.2 \pm 14.6$ \\
Female & 72 & $10-70$ & $28-90$ & $34.3 \pm 14.1$ & $60.3 \pm 16.6$ \\
Combined & 111 & $10-81$ & $27-90$ & $36.1 \pm 15.4$ & $59.9 \pm 15.9$ \\
\hline
\end{tabular}

Toxic MNG is the second leading cause of hyperthyroidism and is more prevalent in populations with greater iodine deficiency. It is commoner in older women $[25,26]$ with a longstanding previous multinodular goiter in which one of the nodules attains functional autonomy. The prevalence of hyperthyroidism in community-based studies has been estimated [27] as approximately 5 to 10 times more common in women than in men; the incidence is similar among Caucasian and Asian population, but lower among African Americans $[15,28]$. In the present study also the great majority of the patients $(65 \%)$ are from female population. However, no statistical significant difference has been found by gender among the uptake values at $\mathrm{p}<0.05$.

All 111 subjects according to their age were classified into four study groups: children (0-20 years), young (21-40 years), adult (41-60 years) and old age (> 60 years). Table 2 presents the 2 and $24 \mathrm{~h}$ uptake values in different study groups. On comparing the uptake 
values in different age groups higher mean values at $2 \mathrm{~h}$ measurement was found in children followed by young and adult. On the contrary, mean uptake at $24 \mathrm{~h}$ measurement was found to be elevated in young and remains nearly unaffected during other age groups.

Table 2. Uptake profile in different age groups $(n=111)$.

\begin{tabular}{l|c|c|c|c|c}
\hline Age & \multirow{2}{*}{$n$} & \multicolumn{2}{|c|}{ RAIU range (\%) at } & \multicolumn{2}{c}{ Mean \pm SD } \\
\cline { 3 - 6 } Group & & $2 \mathrm{~h}$ & $24 \mathrm{~h}$ & $2 \mathrm{~h}$ & $24 \mathrm{~h}$ \\
\hline Children & 4 & $30-66$ & $27-73$ & $44.0 \pm 14.2$ & $55.8 \pm 18.0$ \\
Young & 55 & $11-81$ & $32-90$ & $34.2 \pm 15.4$ & $58.7 \pm 15.1$ \\
Adult & 45 & $10-72$ & $31-86$ & $29.8 \pm 13.6$ & $52.8 \pm 14.8$ \\
Old & 7 & $12-57$ & $31-74$ & $35.0 \pm 16.6$ & $54.6 \pm 15.4$ \\
\hline
\end{tabular}

The age and sex are two important considerations to choose the sample in the study of thyroid function. Patients younger than 40 years are at the highest risk for the development of Graves' disease [29]. Hyperthyroidism with MNG typically occurs in patients older than 40 years with a long-standing goiter, and has a more insidious onset than Graves' disease [30]. As many as $15 \%$ of cases of hyperthyroidism occur in patients older than 60 years. The present study revealed that in Bangladesh most of cases of hyperthyroidism occur in the young and adult groups (age: 21-60 years), and therefore, they are at higher risk.

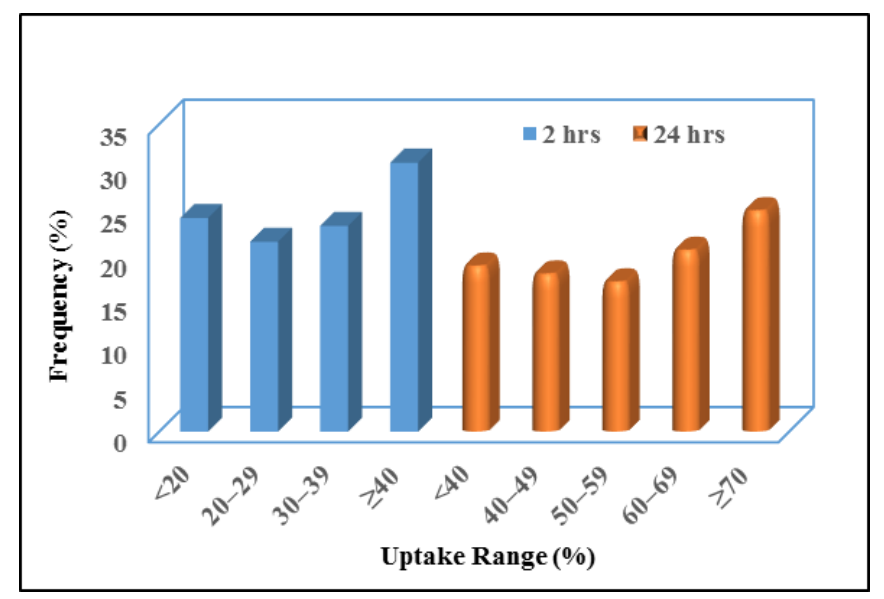

Fig. 1.2 and $24 \mathrm{~h}$ uptake histogram measured in the present study.

The frequency histograms of RAIU values for 2 and $24 \mathrm{~h}$ are depicted in Fig. 1. On comparing the uptake range, the present study observed that a great majority of studied hyperthyroid patients exhibit higher uptake values for both 2 and $24 \mathrm{~h}$ measurements. It is evident that about 55\% patients have $2 \mathrm{~h}$ RAIU more than $30 \%$ and for $24 \mathrm{~h}$ about $50 \%$ patients have uptake values more than $60 \%$. This may be due to the multinodular goiter, 
which is irregular thyroid enlargement containing both functioning and non-functioning nodules.

\section{Conclusion}

A study of thyroid physiology using radioactive iodine uptake and scintigraphy over 111 hyperthyroid patients: female $65 \%$ and male $35 \%$ are presented. The uptake study was performed by oral administration of $4.5-10.0 \mu \mathrm{Ci}$ of ${ }^{131} \mathrm{I}$ as sodium-iodide and counting the radioactivity at $6 \mathrm{~cm}$ using a gamma probe, whereas thyroid scintigraphy was performed $20 \mathrm{~min}$ after an intravenous injection of $2.0-4.0 \mathrm{mCi}$ of ${ }^{99 \mathrm{~m}} \mathrm{Tc}$-pertechnetate. The majority of the study subjects were from female, which is fairly in good agreement with the reported values. The present study provides a good separation of hyperthyroid patients and none of them had uptake value within or below the normal range at both 2 and $24 \mathrm{~h}$ measurements. The ranges of RAIU values measured at 2 and $24 \mathrm{~h}$ were found to range from 10 to $81 \%$ with average \pm SD of $36.1 \pm 15.4 \%$ and from 27 to $90 \%$ with average \pm SD of $59.9 \pm 15.9 \%$, respectively. It is also revealed that a great majority of the hyperthyroid patients are from older age group, which is in accord with the previous studies.

\section{Acknowledgment}

The co-operative help from M. Asaduzzaman and M. A. Rahim, Technicians and all other staffs of INMAS, Dhaka are appreciated.

\section{References}

1. S. Reza, Basic Human Anatomy and Physiology (Mediaplex Publisher and Distributor, Dhaka, Bangladesh, 2011) Chapter 18, pp. 193-202.

2. W. F. Ganong, Review of Medical Physiology (Appleton and Lange, California, 1995) pp. 315.

3. W. F. Ganong, The Thyroid Gland in Review of Medical Physiology, $20^{\text {th }}$ Edition (The MeGraw Hill Companies, New York, 2011) pp. 307-21.

4. Kopf Thyroid Gland, Ohlone Center Lecture Paper, April 17 (2007).

5. J. J. Bongers-Schokking, Pre and Postnatal Brain Development in Neonates with Congenital Hypothyroidism, J Pe-diatr Endocrinol Metab. 14 (Suppl 6) 1463-68 (2001).

6. J. Rovet and D. Daneman, Drugs 5, 141 (2003). https://doi.org/10.2165/00128072-20030503000001

7. R. Z. Klein and M. L Mitchell, Horm. Res. 52, 55 (1999).

8. T. Yasuda, H. Ohnishi, K. Wataki, M. Minagawa, K. Minamitani, and H. Niimi, J. Clin. Endocrinol Metab. 84, 2630 (1999).

9. S. C. Boyages and J. P. Halpern, Thyroid 3, 59 (1993). https://doi.org/10.1089/thy.1993.3.59

10. G. W. Anderson, Front. Neuroendocrinol. 22, 1 (2001). https://doi.org/10.1006/frne.2000.0208

11. J. Kohrle, Thyroid Hormone Metabolism and Action in the Brain and Pituitary (Acta Med, Austriaca, 2000) 27, pp. 1-7. https://doi.org/10.1046/j.1563-2571.2000.00101.x

12. N. Koibuchi and W. W Chin, Trends Endocrinol. Metab. 11, 123 (2000). https://doi.org/10.1016/S1043-2760(00)00238-1

13. J. L. Leonard and A. P. Farwell, Thyroid 7, 147 (1997). 
14. T. A. Howlett, "Endocrine Disease," in Clinical Medicine, $6{ }^{\text {th }}$ Edition, ed. P. Kumar et al. (Edinburgh, Elseviers Saunders, 2005).

15. A. P. Weetman, J. Med. 343, 1236 (2000).

16. D. S. Weigle, T. M. Hooton, and B. Toivola, J. Clin. Pharm. Ther. 21, 29 (1996). https://doi.org/10.1111/j.1365-2710.1996.tb00345.x

17. M. N. Maisey, K. E. Britton, and B. D. Collier, Clinical Nuclear Medicine, $3^{\text {rd }}$ Edition, (Chapman \& Hall, London, 1998). https://doi.org/10.1007/978-1-4899-3356-0

18. I. J. Chopra, S. Y. Wu, and G. N. Teco, J. Clin. Endocrinol. Metab. 75, 189 (1992).

19. A. A. Sharif, A. M. Abujbara, S. Chiacchio, K. M. Ajlouni, and G. Mariani, Hell. J. Nucl. Med. 13, 132 (2010).

20. Individual Monitoring for Intakes of Radionuclides by Workers: Design and Interpretation, Int. Commission on Radiological Protection, Ann. ICRP 19(1-3) 1-315 (1988).

21. ICRP, Age-dependent Doses to Members of the Public from Intake of Radionuclides, Part 2 Ingestion Dose Coefficients, A Report of a Task group of Committee 2, The International Commission on Radiological Rrotection(Elsevier Health Sciences, 1994) 2.

22. D. Salvatore, T. Davies, M. Schlumberger, I. Hay, and P. Larsen, Thyroid Physiology and Diagnostic Evaluation of Patients with Thyroid Disorders in Williams Textbook of Endocrinology, ed. S. Melmed et al., $12^{\text {th }}$ Edition (Elsevier, Philadelphia, USA, 2011) 12, pp. 327-350.

23. M. S. Rosenthal, The Thyroid Sourcebook (McGraw-Hill, 2009).

24. H. R. Balon, E. B. Silberstein, D. A. Meier, N. D. Charkes, H. D. Royal, S. D. Sarkar, and K. J. Donohoe, Society of Nuclear Medicine Procedure Guideline for Thyroid Uptake Measurement. Version 3.0, 1-3 (2006).

25. S. L. Robbins, R. S. Cotran, V. Kumar, and T. Collins, Pathologic Basis of Disease, $6^{\text {th }}$ Edition (W.B. Saunders, Philadelphia, 1999) pp. 1130-1141.

26. H. A. Zieeman, J. H. O'Malley, and F. H. Fahey, Cardiac System, Nuclear Medicine-The Requisites in Radiology, $3^{\text {rd }}$ Edition (Elsevier Mosby, Philadelphia, 2006) 506.

27. W. M. Turnbridge, D. C. Evered, R. Hall, D. Appleton, M. Brewis, and F. Clark, Clin. Endocrinol. 7, 481 (1977). https://doi.org/10.1111/j.1365-2265.1977.tb01340.x

28. L. N. Metchick, V. Carlone, and B. L. Haag, Hosp. Physician 41, 46 (2005).

29. S. Melmed, K. S. Polonsky, P. R. Larsen, and H. M. Kronenberg, Williams's Textbook of Endocrinology (Elsevier Health Sciences, 2015).

30. Corvilain, J. F. Dumont, and G. Vassart, Toxic Adenoma and Toxic Multinodular Goiter, In: Werner \& Ingbar's the Thyroid: A Fundamental and Clinical Text, ed. S. C. Werner et al., $8^{\text {th }}$ Edition (Philadelphia: Lippincott Williams \& Wilkins, 2000) pp. 564-572. 